patients $(6.3 \%)$ presented with only positive anti-centromere. CP was normal in 191 patients, while in 45 patients scleroderma pattern was observed and in 19 patients nonspecific pattern suggestive of SAD was seen. Capillaroscopic findings: in each of the 23 patients diagnosed with SSc, 21 patients had scleroderma pattern. Of the 6 patients with SLE, $\mathrm{CP}$ was normal in 4 patients, while one patient had abundant tortuosity. Likewise, the 6 patients with Sjögren's syndrome, only one patient had a nonspecific pattern suggestive of SAD. Of the 7 patients with MCTD, four had normal CP, two had a scleroderma pattern and one had tortuous pattern. The 2 patients with overlap (myopathy-scleroderma and Lupus-scleroderma) both had a pathological CP with scleroderma pattern. Conclusion: Our study demonstrates that the evidence of scleroderma pattern is very specific of SSc. However, in certain diseases such as MCTD, overlap syndromes and inflammatory myopathies, we can also see this pattern. In other SAD, CP is usually normal or may show some nonspecific changes.

References: The contribution of capillaroscopy to the differential diagnosis of connective autoimmune diseases. Best Practice \& Research Clinical Rheumatology Vol. 21, No. 6, pp. 1093-1108, 2007

Disclosure of Interests: None declared

DOI: 10.1136/annrheumdis-2019-eular.4133

\section{AB0674 RETROSPECTIVE STUDY OF A COHORT OF PATIENTS WITH SYSTEMIC SCLEROSIS IN A TERTIARY CARE HOSPITAL}

David Moyano Bueno ${ }^{1}$, Luis Gómez-Lechón ${ }^{2}$, Olga Martínez González ${ }^{2}$, Ana Isabel Turrión ${ }^{2}$, Carlos A. Montilla-Morales ${ }^{2}$, Cristina Hidalgo ${ }^{2} .{ }^{1}$ Complejo $^{2}$ Asistencial Universitario de Salamanca, Dermatology, Salamanca, Spain; ${ }^{2}$ Complejo Asistencial Universitario de Salamanca, Rheumatology, Salamanca, Spain

Background: Systemic sclerosis (SS) is an autoimmune disease of unknown etiology, characterized by the presence of fibrosis and vasculopathy in skin and multiple internal organs such as the lungs, the kidneys and the digestive tract. The course of the disease is unpredictable and could remain relatively stable or have a rapid evolution. Multiple studies have been carried out to determine the clinical characteristics and survival prognosis on SS patients.

Objectives: To analyze the demographic characteristics, clinical features, treatment and prognosis in a SS disease cohort.

Methods: We performed an observational and retrospective study of patients whit SS. The patients had been attended by the Rheumatology department of a tertiary care hospital. We collected demographic, clinical and analytical variables, as well as treatment and prognosis. We classified the disease employing the LeRoy and Medsger, VEDOSS criteria and 2013 ACR/EULAR criteria.

Results: Of our 43 patients, $36(83.7 \%)$ were female and only $7(16.3 \%)$ were male. The average age was 60.4 years (SD 15.6), the average age at diagnosis was 53.3 years (SD 17.6) and the mean time of evolution of the disease was 7.9 years (SD 6.3). Of all the patients, 3 patients $(6.9 \%)$ died, the mean age at death being 53.6 years (SD 23.7) and the mean time from diagnosis to death of 19 years (SD 10.1). The most frequently ocurring presentation was limited SS (with 18 patients $(41.9 \%)$, followed by preescleroderma with 14 patients (32.6\%), diffuse SS with 6 patients $(14 \%)$ and escleroderma sine escleroderma with 2 patients $(4.7 \%)$. Three patients $(7 \%)$ were labeled with MCTD. SS was associated with other autoimmune diseases in $20 \%$ of patients. Five $(11.6 \%)$ patients developed neoplasms throughout the course of the study. The rest of the clinical characteristics are listed in Table 1 and 2, as well as the strength of association of these with the type of SS, calculated using chi square and Fischer test.

Conclusion: Worthy of noting in our cohort is the absence of scleroderma in more than $40 \%$ of our patients, probably because the new criteria have allowed us to diagnose the disease at an earlier stage and also due to the scarce frequency of puffy fingers with respect to other larger series. Digestive involvement was the most frequent visceral manifestation, followed by pulmonary manifestations, specifically interstitial lung disease (ILD). Despite the small sample size, lung disease was significantly associated with the two forms of systemic sclerosis, but not with the antibody pattern. Both the ILD and the pulmonary arterial hypertension (PAH) were more frequent in patients with SSd. Mortality in all cases was due to interstitial lung involvement. As is frequently described, SS is associated with other systemic autoimmune diseases, constituting an overlap syndrome.

\section{REFERENCES}

[1] Cañete Crespillo, J. (2008). Manual SER de las enfermedades reumáticas. Madrid: Editorial Médica Panamericana.

[2] Dougherty, D., Kwakkenbos, L., Carrier, M., Salazar, G., Assassi, S. Baron, M., Bartlett, S., Furst, D., Gottesman, K., van den Hoogen, F., Malcarne, V., Mouthon, L., Nielson, W., Poiraudeau, S., Sauvé, M., Boire, G. Bruns, A., Chung, L., Denton, C., Dunne, J., Fortin, P., Frech, T., Gill, A. Gordon, J., Herrick, A., Hinchcliff, M., Hudson, M., Johnson, S., Jones, N., Kafaja, S., Larché, M., Manning, J., Pope, J., Spiera, R., Steen, V., Sutton E., Thorne, C., Wilcox, P., Thombs, B. and Mayes, M. (2018). The Scleroderma Patient-Centered Intervention Network Cohort: baseline clinical features and comparison with other large scleroderma cohorts. Rheumatology, 57(9), pp.1623-1631.

[3] CLINICAL FEATURES AND PROGNOSTIC FACTORS FOR SYSTEMIC SCLEROSIS RELATED INTERSTITIAL LUNG DISEASE. (2018). Respirology, 23, pp.155-155.

Disclosure of Interests: None declared

DOI: 10.1136/annrheumdis-2019-eular.7361

\section{$\mathrm{AB} 0675$ \\ DECREASED CAPILLARY DENSITY IS ASSOCIATED WITH DECREASED HAND MOBILITY IN SYSTEMIC SCLEROSIS}

Gabriella Nagy, Antonietta Kovács, Dalma Komjati, Renata Szijártó, Tunde Minier, Gabor Kumanovics, László Czirják, Cecília Varjú. University of Pécs, Department of Rheumatology and Immunology, Pécs, Hungary

Background: Nailfold videocapillaroscopy (NVC) is a simple method to evaluate capillary density and morphology. Systemic sclerosis (SSc) is characterized with decreased hand mobility and joint contractures evolving in hands in early disease stage. Movement ability (MA) of hands can be measured with different methods including Hand Mobility Index in Scleroderma (HAMIS), hand anatomic index (HAI), delta finger-to-palm index ( $\triangle \mathrm{FTP})$, and number of joints with decreased range of motion (joint contractures-JC).

Objectives: To examine correlation between capillary density and MA of hands in patients with SSc.

Methods: 136 patients with SSc underwent detailed examination of MA and capillary density measured with videocapillaroscop. 70 patients had limited cutaneous SSc (ICSSc) and 66 had diffuse cutaneous SSc (dcSSc). 48 patients had $\leq 5$ years of disease duration (early SSc) and 88 patients had disease duration $>5$ years (late SSc) calculated from the first non-Raynaud symptoms.

Results: DcSSc patients had significantly higher HAMIS score than IcSSc patients $(4.5 / 1.5 ; 6.5 /$ vs. $2 / 0.5 ; 4.5 / ; p<0.01)$. HAMIS score showed negative correlation with capillary density in the entire cohort (rho: -0.269 , $p<0.01$ ) and in dcSSc patients (rho:-0.487; $p<0.0001$ ), but not in IcSSc ones.

HAI showed a significantly higher value in IcSSc patients than in dcSSc patients $(3.79 / 3.18 ; 4.39 / v s .3 .19 / 2.64 ; 3.76 /, \quad p<0.01)$. Significant positive correlation between $\mathrm{HAl}$ and capillary density was found in dcSSc patients (rho: $0.377, p<0.01$ )

DcSSc patients showed significantly lower $\triangle$ FTP value than IcSSc patients $(73.88 / 65.63 ; 87.00 /$ vs. $82.81 / 73.63 ; 90.5 / ; p<0.05)$. Positive correlation was found between capillary density and $\triangle \mathrm{FTP}$ in the entire cohort, in dcSSc patients even if dcSSc was examined separately as early dcSSc and late dcSSc. No significant correlation was found between capillary density and $\triangle \mathrm{FTP}$ in IcSSc patients.

The number of JC was significantly higher in dcSSc patients than in IcSSc patients $(16 / 0 ; 28 /$ vs. 0/0;11/; $p<0.01)$, and no statistically significant difference was found between early SSc patients and late SSc patients. Strong negative correlation was found between JC count and capillary density in the entire cohort (rho -0.376; $\mathrm{p}<0.0001$ ), in dcSSc patients (rho $-0.501 ; p<0.0001$ ), in early SSc patients (rho-0.583; $p<0.0001$ ) and late SSc patients (rho $-0,262 \mathrm{p}<0.05$ ), but not in IcSSc patients.

Conclusion: Decreased capillary density correlated with decreased hand mobility and higher number of JCs. Tissue ischemia may play role in the development of joint contractures and it might be a contributing factor to decreased hand mobility impairment in SSc.

\section{REFERENCES}

[1] Torok KS, Baker NA, Lucas M, et al. Reliability and validity of the delta finger-to-palm (FTP), a new measure of finger range of motion in systemic sclerosis. Clin Exp Rheumatol. 2010;28(2)(Suppl 58):S28-S36.

[2] Sandqvist G, Nilsson JA, Wuttge DM, Hesselstrand R. Development of a modified hand mobility in scleroderma (HAMIS) test and its potential as an 